Vietnam Journal of Mechanics, VAST, Vol.40, No. 4 (2018), pp. 387-395

DOI: https://doi.org/10.15625/0866-7136/13207

\title{
BACKONE EQUATION OF STATE FOR CIS-1, 3, 3, 3-TETRAFLUOROPROPENE (R1234ZE(Z))
}

\author{
Phan Thi Thu Huong ${ }^{1}$, Lai Ngoc Anh ${ }^{2, *}$ \\ ${ }^{1}$ Nam Dinh University of Technology Education, Nam Dinh, Vietnam \\ ${ }^{2}$ Hanoi University of Science and Technology, Hanoi, Vietnam \\ *E-mail: anhngoclai@yahoo.com \\ Received October 19, 2018
}

\begin{abstract}
This paper presents the study on the determination of the thermodynamic properties of Cis-1,3,3,3-tetrafluoropropene $(\mathrm{R} 1234 \mathrm{ze}(\mathrm{Z}))$ with the BACKONE equation of state. The BACKONE's characteristic temperature $T_{0}$, characteristic density $\rho_{0}$, anisotropy factor $\alpha$, and reduce quarupole moment $Q^{* 2}$ were found by fitting the BACKONE EOS to experimental data of vapor pressure and saturated liquid density. All thermodynamic properties such as vapor pressure, pressure in gaseous phase, saturated liquid density, and liquid density can be determined easily from the found molecular characteristic properties. Thermodynamic properties of the R1234ze(Z) were evaluated with available experimental data. Average absolute deviations between calculated vapor pressure data and experimental data were $0.43 \%$. Average absolute deviations between calculated saturated liquid density data and experimental data were $0.43 \%$. In the prediction of the thermodynamic properties, average absolute deviations between calculated liquid density data and experimental data were $0.68 \%$ and average absolute deviations between calculated gas density data and experimental data were $1.6 \%$.
\end{abstract}

Keywords: HFO-1234ze(Z), R1234ze(Z), thermodynamic properties, BACKONE equation of state (EOS).

\section{INTRODUCTION}

R245fa was considered as the alternative refrigerant of R114 in the past two decades. However, global warming potential (GWP) of R245fa is 1020 which is much higher than the recent requirement for the fourth generation of the refrigerants. One of the most potential alternative refrigerants for R254fa and R114 in medium and high temperature heat pump applications is Cis-1,3,3,3-tetrafluoropropene (HFO1234ze(Z) or R1234ze(Z)) as its GWP is only 1.4 [1] and its heat of evaporation is similar to that of R245fa, Fukuda [2], Kondou [3], Longo [4], Petr [5], Brown [6], Zhang [7].

Experimental study on the basic thermodynamic properties of $R 1234 z e(Z)$ such as vapor pressure, saturated liquid density, gas pressure, liquid density, speed of sound has been carried out by various scientists Higashi [8], Fedele [9], Brown [10], Kondo [11],

(C) 2018 Vietnam Academy of Science and Technology 
Katsuyuki [12], Lago [13]. From the basic experimental data, Akasaka [14] and Brown [15] developed multiparameter EOS for the R1234ze(Z).

Multiparameter EOS is the most accurate EOS in the available experimental data range but it is not accurate for outside of the available experimental data range. The reason is that it is only polynomial model having multiparameters and the parameters don't have any physical meanings.

In order to fill the lack of accurate thermodynamic properties where experimental data are not available, molecular base EOS such as PC-SAFT EOS and BACKONE EOS should be used. Another advantage of the PC-SAFT EOS and the BACKONE EOS is that they are easily in extension to mixtures. Recent study shows that the BACKONE EOS is more accurate than PC-SAFT EOS [16], so the BACKONE EOS is used in the determination of the thermodynamic properties of R1234ze(Z) in this study.

\section{BACKONE EOS}

The BACKONE EOS is molecular based EOS constructed from molecular interaction theory. This EOS can be used to calculate all type of thermodynamic properties accurately such as pvT data and enthalpy, entropy, heat capacity, and so on. In the BACKONE EOS, Helmholtz energy is written as the sum of molecular hard-body contribution $F_{H}$, attractive dispersion force contribution $\mathrm{F}_{A}$, dipolar contribution $F_{D}$ and quadrupolar contribution $F_{Q}$.

$$
\frac{F}{R T}=\frac{F_{H}}{R T}+\frac{F_{A}}{R T}+\frac{F_{D}}{R T}+\frac{F_{Q}}{R T} .
$$

The BACKONE EOS has only 3 to 5 parameters [17]. For nonpolar fluids, The BACKONE EOS has only three parameters as characteristic temperature $T_{0}$, characteristic density $\rho_{0}$, and anisotropy factor $\alpha$. For polar fluids, additional reduced quadrupole moment $\mathrm{Q}^{* 2}$ is used for multipolar fluids and reduced dipole moment $\mu^{* 2}$ is used for dipolar fluids. All of the parameters of the BACKONE EOS can be found by fitting the BACKONE EOS to experimental data for vapor pressure and saturated liquid density. These parameters can be used in calculate state properties in full fluid region, e.g. in liquid phase, in gas phase, and in two-phase region. If ideal gas heat capacity is available, The BACKONE EOS can also be used to calculate all caloric properties such as enthalpy, entropy, heat capacity, heat of vaporization.

\section{EQUATION OF STATE FOR HFO-1234ZE(Z)}

\subsection{General information}

Molecular structure of $\mathrm{R} 1234 \mathrm{ze}(\mathrm{Z})$ is shown in Fig. 1. This substance has 4 fluorine $(\mathrm{F})$ atoms, 3 carbon $(\mathrm{C})$ atoms, and 2 hydrogen $(\mathrm{H})$ atoms thus molecular weight of $\mathrm{R} 1234 \mathrm{ze}(\mathrm{Z})$ is $0.1140416 \mathrm{~kg} / \mathrm{mol}$. In the safety classification, $\mathrm{R} 1234 \mathrm{ze}(\mathrm{Z})$ is expected to be A2L as similar to R1234ze(E). In environmental aspect, R1234ze(Z) is environmental friendly substance having ozone depletion potential (ODP) of 0 and $\mathrm{GWP}_{100}$ of 1.4 [1]. 


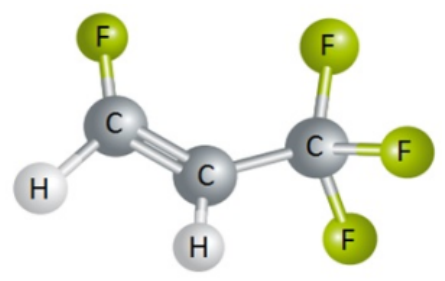

Fig. 1. Structure of R1234ze(Z)

\subsection{Available experimental data}

Critical temperature $\left(T_{c}\right)$, critical pressure $\left(p_{c}\right)$, and saturated liquid density of R1234ze(Z) were published by Brown et al. [15] and Higashi et al. [8], shown in Tab. 1. The data published by Brown et al. [15] are predicted one whilst the data published by Higashi et al. [8] are experimental data. The experimental data are more accurate, e.g. uncertainty of temperature is $0.03 \mathrm{~K}$ and uncertainty of density is $5 \mathrm{~kg} / \mathrm{m}^{3}$. Thus, in this study, experimental data of Higashi et al. [8] were used.

Table 1. Critical properties of R1234ze(Z) and sources

\begin{tabular}{cccc}
\hline$T_{c}, \mathrm{~K}$ & $p_{c}, \mathrm{MPa}$ & $\rho_{c}, \mathrm{~mol} / \mathrm{dm}^{3}$ & Sources \\
\hline 423.27 & 3.533 & 4.1213 & Higashi [8] \\
426.8 & 3.970 & 4.1476 & Brown [15] \\
\hline
\end{tabular}

Table 2. Experimental vapor pressure of R1234ze(Z)

\begin{tabular}{ccrc}
\hline Sources & Number experimental data points & $T_{\min -\max }, \mathrm{K}$ & $P_{\min -\max }, \mathrm{MPa}$ \\
\hline Fedele [9] (Lab ITC-CNR) & 36 & $283-353$ & $0.103-0.863$ \\
Fedele [9] (Lab UnivPM) & 28 & $238-372$ & $0.012-1.336$ \\
Higashi [8] & 19 & $310-420$ & $0.263-3.333$ \\
Katsuyuki [12] & 22 & $300-400$ & $0.186-2.309$ \\
\hline
\end{tabular}

Available experimental data for vapor pressure $\left(p_{s}\right)$ of $\mathrm{R} 1234 \mathrm{ze}(Z)$ were given in Tab. 2. Tab. 2 includes sources, number of experimental data points, temperature ranges and vapor pressure ranges. In details, a vapor-liquid equilibrium apparatus of the Istituto per le Tecnologie della Costruzione of the Consiglio Nazionale delle Ricerche (ITC$\mathrm{CNR})$ was used to measure the vapor pressure of $\mathrm{R} 1234 \mathrm{ze}(\mathrm{Z})$ for temperature ranging from $283.15 \mathrm{~K}$ to $353.16 \mathrm{~K}$ [9]. The uncertainty of temperature and pressure were said to be about $0.03 \mathrm{~K}$ and less than $1 \mathrm{kPa}$, respectively. The apparatus was also validated by measuring vapor pressure of R134a as a reference fluid. The average absolute deviation of measured vapor pressure for temperature range from $255.16 \mathrm{~K}$ to $337.15 \mathrm{~K}$ is $0.02 \%$. Another apparatus, used to measure the vapor pressure in the study of Fedele [9], 
is isochoric apparatus. The uncertainty of temperature and pressure of this apparatus is similar to that of the vapor-liquid equilibrium apparatus. The average absolute deviation of measured reference vapor pressure of is $0.03 \%$. Higashi [8] published 19 experimental vapor pressure data points for temperature ranging from $310 \mathrm{~K}$ to $420 \mathrm{~K}$. The uncertainty of the measured pressure was reported to be within $\pm 1 \mathrm{kPa}$ for the temperature less than $380 \mathrm{~K}$ and to be within $\pm 2 \mathrm{kPa}$ for the temperature higher than $380 \mathrm{~K}$. The last available experimental data of R1234ze(Z) were published by Katsuyuki [12]. Maximum uncertainty of measured temperature and pressure were said to be $0.01 \mathrm{~K}$ and $0.3 \mathrm{kPa}$, respectively.

Tab. 3 shows experimental saturated vapor and liquid density. Katsuyuki [12] published 22 experimental data points for saturated liquid density with an uncertainty of density of $0.9 \mathrm{~kg} / \mathrm{m}^{3}$. Fedele et al. [18] published 313 experimental data point of liquid density with an uncertainty of about $0.8 \mathrm{~kg} / \mathrm{m}^{3}$. In the study of Higashi et al. [8], the uncertainty of the measured density ranges from $0.2 \mathrm{~kg} / \mathrm{m}^{3}$ to $0.6 \mathrm{~kg} / \mathrm{m}^{3}$. In the study of Fedele et al. [18], stainless steel vibrating tube densimeter was used. The uncertainty of the measured density was reported to be $0.8 \mathrm{~kg} / \mathrm{m}^{3}$.

Table 3. Experimental saturated density and pvT data of R1234ze(Z)

\begin{tabular}{cccccc}
\hline State & Sources & $\begin{array}{c}\text { Number } \\
\text { experimental } \\
\text { data point }\end{array}$ & $\begin{array}{c}\rho_{\min -\max ,} \\
\operatorname{mol} / \mathrm{dm}^{3}\end{array}$ & $\begin{array}{c}T_{\min -\max ,} \\
\mathrm{K}\end{array}$ & $\begin{array}{c}P_{\min -\max } \\
\mathrm{MPa}\end{array}$ \\
\hline Saturated liquid & Higashi [8] & 9 & $4.391-8.786$ & $368-424$ & - \\
Katurated vapor & Higashi [8] & 22 & $7.397-10.691$ & $300-400$ & - \\
pvT & Higashi [8] & 71 & $0.395-4.127$ & $368-424$ & - \\
& Fedele [18] & 313 & $0.397-8.786$ & $360-440$ & $0.94-6.03$ \\
& & & & & \\
\hline
\end{tabular}

\subsection{BACKONE EOS's parameters for R1234ze(Z)}

In this study, BACKONE EOS's parameters for R1234ze(Z) as characteristic temperature $T_{0}$, characteristic density $\rho_{0}$, anisotropy factor $\alpha$ and reduce quarupole moment $Q^{* 2}$ were found by fitting the BACKONE EOS to experimental data for vapor pressure in Tab. 2 and saturated liquid density in Tab. 3. The found characteristic temperature $T_{0}$, characteristic density $\rho_{0}$, anisotropy factor $\alpha$, and reduce quarupole moment $Q^{* 2}$ were $413.825496 \mathrm{~K}, 4.057173 \mathrm{~mol} / 1,1.44052$, and 2.755521, respectively. These parameters can be used to calculate all thermodynamic properties of R1234ze(Z). If ideal gas heat capacity is known, these parameters can be used to calculate all caloric properties also, meaning that all thermodynamic properties of $\mathrm{R} 1234 \mathrm{ze}(\mathrm{Z})$ can be determined from these found parameters and from available ideal gas heat capacity. Detail evaluation and investigation of the BACKONE EOS for R1234ze(Z) will be given in next section. 


\section{EVALUATIONS}

In order to evaluate the accuracy of the BACKONE EOS for R1234ze(Z), molecular characteristics of $\mathrm{R} 1234 \mathrm{ze}(\mathrm{Z})$ in BACKONE EOS were used to calculate the thermodynamic properties of this substance. The calculated data forvapor pressure were then compared with available experimental data of Fedele [9], Higashi [8], and Katsuyuki [12]. The relative difference between calculated data and experimental data as well as the average absolute deviation (AAD) were given in Tab. 4. The Tab. 4 shows that BACKONE's vapor pressures agree well with all available experimental data. The average absolute deviation between calculated data for vapor pressure and all experimental data published by Fedele et al. [9] are only $0.43 \%$. For the convenience of the reader, all the relative differences between calculated data for vapor pressure and experimental data were show in Fig. 2. Fig. 2 shows that the relative differences are mostly within $1 \%$. There exist the difference between experimental data of Fedele et al. [9] and those from Higashi [8] and Katsuyuki [12].

Table 4. Relative difference and ADD between BACKONE's vapor pressure and experimental vapor pressure

\begin{tabular}{ccc}
\hline Experimental data source & Relative difference range, $\%$ & AAD, $\%$ \\
\hline Fedele [9]_Lab ITC_CNR & -0.84 to 0.39 & 0.43 \\
Fedele [9]_Lab UnivPM & -0.65 to 1.58 & 0.54 \\
Higashi [8] & -0.79 to 3.72 & 1.08 \\
Katsuyuki [12] & -2.71 to 1.41 & 0.97 \\
\hline
\end{tabular}

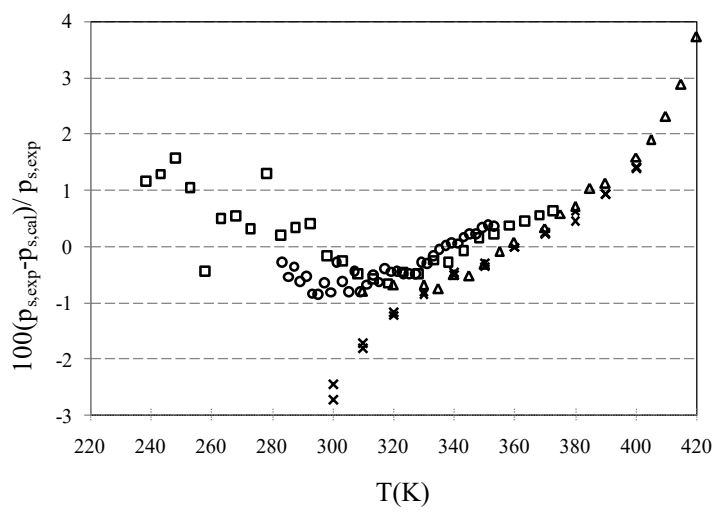

Fig. 2. Relative deviation between BACKONE's vapor pressure $\left(p_{s, c a l}\right)$ and experimental vapor pressure $\left(p_{s, \text { exp }}\right)$ of $\circ$ Fedele [9]_ITC_CNR, Fedele [9]_UnivPM, $\Delta$ Higashi [8], $\times$ Katsuyuki [12]

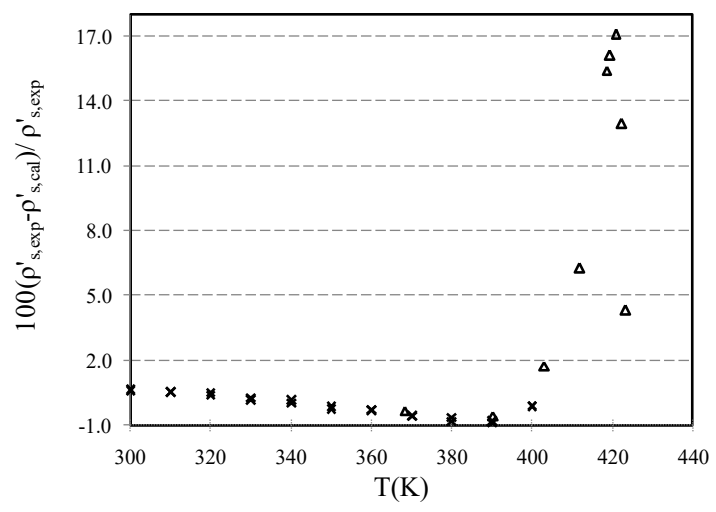

Fig. 3. Deviation of saturated liquid density data $\left(\rho_{s, c a l}^{\prime}\right)$ from the BACKONE EOS and experimental data $\left(\rho_{s, \text { exp }}^{\prime}\right)$ from $\Delta$ Higashi $[8]$ and $\times$ Katsuyuki [12] 
Deviation between BACKONE's saturated liquid density data and those from Higashi [8] and Katsuyuki [12] are shown in Fig. 3. The AAD between calculated values and experimental data of Katsuyuki [12] are $0.43 \%$. This proves the reliability of the BACKONE EOS for R1234ze(Z). Deviation between calculated saturated liquid density and experimental data published by Higashi [8] increase with the increase of temperature. The closer to the critical point the larger the deviation. Similar to the saturated liquid density, the deviations between calculated vapor density and experimental data increase as the temperature increase, Fig. 4. In order to investigate the accuracy of the BACKONE EOS in higher temperature range, comparison between calculated density data and experimental density data in single phase fluid region having temperature higher than critical temperature are shown in Fig. 5.

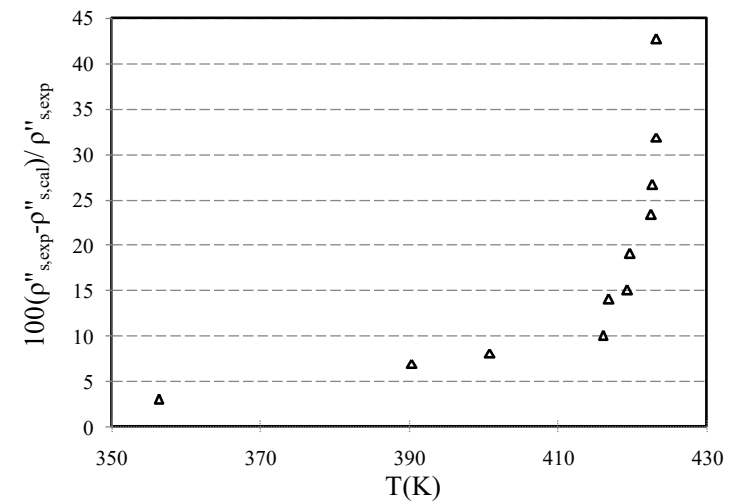

Fig. 4. Deviation of saturated vapor density data $\left(\rho_{s, c a l}^{\prime \prime}\right)$ from the BACKONE EOS and experimental data $\left(\rho_{s, \exp }^{\prime \prime}\right)$ from $\Delta$ Higashi [8]

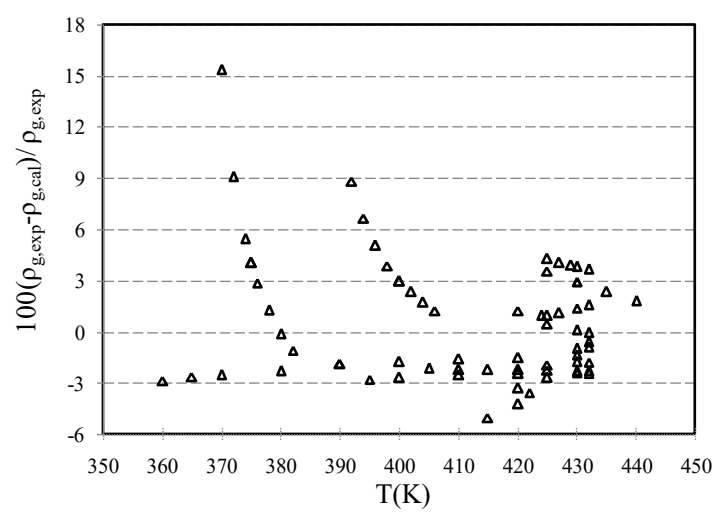

Fig. 5. Deviation of gaseous density data $\left(\rho_{g, c a l}\right)$ from the BACKONE EOS and experimental data $\left(\rho_{g, \exp }\right)$ of Higashi [8]

Fig. 5 shows deviations between the BACKONE's calculated density data and experimental data of Higashi [8], and Fedele [18]. Deviations of the density around critical region and for the temperature range higher than critical temperature are within $3 \%$. It means that the BACKONE EOS is still reliable. In Fig. 3 and Fig. 4, there are some data having high deviations whilst for these 71 experimental data points, the error in the critical region are only within 3\%. Relative deviations between calculated value and experimental data for 71 data points range from $-5.05 \%$ to $15.37 \%$. The AAD for 71 data points are $2.79 \%$. Thus, some experimental data may have something wrong. Fig. 5 also shows some points having high deviation in low temperature range. In order to investigate this situation, further investigation for the deviations between BACKONE's calculated density data and experimental data for low temperature range is shown in Fig. 6 and Fig. 7.

As shown in Fig. 6, relative deviations between BACKONE's gas density data $\left(\rho_{g, \text { cal }}\right)$ and experimental gas density data $\left(\rho_{g, \text { exp }}\right)$ of Fedele et al. [18] at different temperature range from $0.1 \%$ to $3.54 \%$. The AAD between the calculated data and experimental ones for 98 available data points are $1.6 \%$. In the construction of the BACKONE EOS, only 
experimental data for vapor pressure and saturated liquid density were used. The small AAD prove the predictive power as well as the reliability of the BACKONE EOS for this R1234ze(Z). All the deviations in Fig. 6 have relative smooth trend and the deviations are small. However as shown in Fig. 5, there are some experimental data having non-smooth deviation trend. The strange deviation of some points in Fig. 5 should be evaluated with other available experimental data sets to confirm the reliability of these data points. At the moment, no other similar experimental data are available so further evaluation of these data points are impossible.

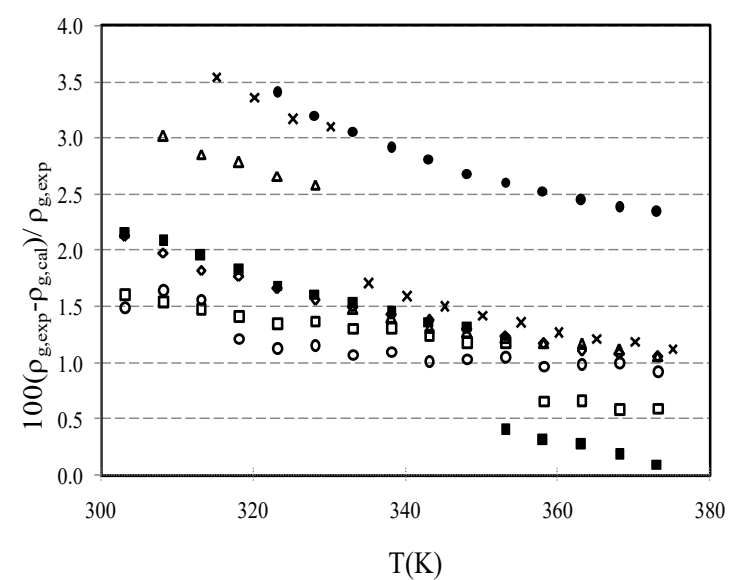

Fig. 6. Deviation of gaseous density $\left(\rho_{g, c a l}\right)$ from the BACKONE EOS and experimental gas density data $\left(\rho_{g, \text { exp }}\right)$ of Fedele et al. [18] at different temperature for various density cases: $\circ v=0.26 \mathrm{~m}^{3} / \mathrm{kg}, v=0.185 \mathrm{~m}^{3} / \mathrm{kg}$, $\Delta v=0.095 \mathrm{~m}^{3} / \mathrm{kg}, \times v=0.077 \mathrm{~m}^{3} / \mathrm{kg}$, $\diamond v=0.111 \mathrm{~m}^{3} / \mathrm{kg}, \bullet v=0.107 \mathrm{~m}^{3} / \mathrm{kg}$, $v=0.057 \mathrm{~m}^{3} / \mathrm{kg}$

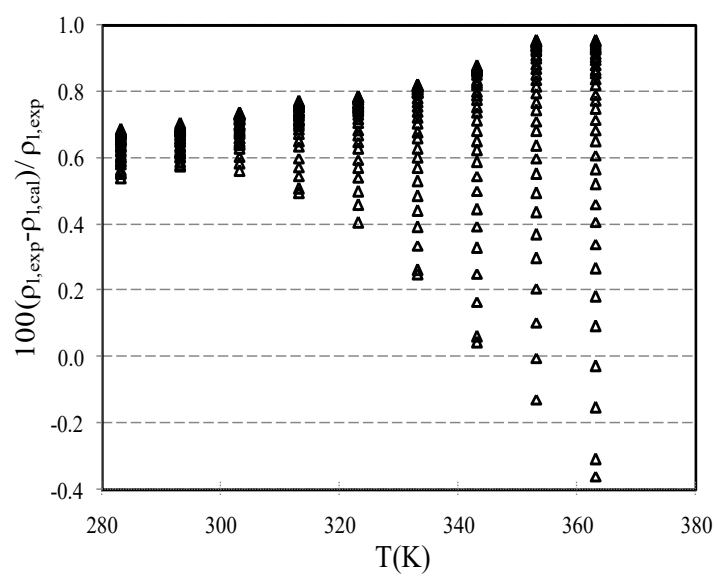

Fig. 7. Deviation of liquid density data $\left(\rho_{l, c a l}\right)$ from the BACKONE EOS and experimental data $\left(\rho_{l, \text { exp }}\right)$ of Higashi [8]

As shown in Fig. 7, the relative deviations between the BACKONE's calculated liquid density data $\left(\rho_{l, \text { cal }}\right)$ and experimental data $\left(\rho_{l, \exp }\right)$ of Higashi [8] range from $-0.36 \%$ to $0.95 \%$. The AAD for 312 data points are $0.68 \%$. It should be notice that, in the construction of BACKONE EOS, only experimental data for vapor pressure and saturated liquid density were used. Thus, the prediction of BACKONE EOS with the AAD of only $0.68 \%$ is very good. This proves the accurate and reliability of the BACKONE EOS.

\section{CONCLUSION}

Equation of state for R1234ze(Z) was developed by using experimental data for vapor pressure and saturated liquid density. All thermodynamic properties of R1234ze(Z) in both single phase and two-phase regions can be calculated from the found BACKONE's parameters. The accuracy of the calculated thermodynamic properties from this 
study was evaluated by comparison with available experimental data. In details, average absolute deviations between calculated vapor pressure data and experimental data of Fedele [9] were $0.43 \%$. Average absolute deviations between calculated saturated liquid density data and experimental data of Katsuyuki [12] were $0.43 \%$. In the prediction of the thermodynamic properties, average absolute deviations between calculated liquid density data and experimental data were $0.68 \%$ and average absolute deviations between calculated gas density data and experimental data were $1.6 \%$.

\section{ACKNOWLEDGMENT}

This research is funded by Vietnam National Foundation for Science and Technology Development (NAFOSTED) under grant number 107.03-2016.10. The authors gratefully acknowledge financial support by the NAFOSTED.

\section{REFERENCES}

[1] M. O. Mclinden, A. F. Kazakov, J. S. Brown, and P. A. Domanski. A thermodynamic analysis of refrigerants: Possibilities and tradeoffs for Low-GWP refrigerants. International Journal of Refrigeration, 38, (2014), pp. 80-92. https://doi.org/10.1016/j.ijrefrig.2013.09.032.

[2] S. Fukuda, C. Kondou, N. Takata, and S. Koyama. Low GWP refrigerants R1234ze (E) and R1234ze (Z) for high temperature heat pumps. International journal of Refrigeration, 40, (2014), pp. 161-173. https://doi.org/10.1016/j.ijrefrig.2013.10.014.

[3] C. Kondou and S. Koyama. Thermodynamic assessment of high-temperature heat pumps using Low-GWP HFO refrigerants for heat recovery. International Journal of Refrigeration, 53, (2015), pp. 126-141. https://doi.org/10.1016/j.ijrefrig.2014.09.018.

[4] G. A. Longo, C. Zilio, G. Righetti, and J. S. Brown. Experimental assessment of the low GWP refrigerant HFO-1234ze (Z) for high temperature heat pumps. Experimental Thermal and Fluid Science, 57, (2014), pp. 293-300. https://doi.org/10.1016/j.expthermflusci.2014.05.004.

[5] P. Petr and G. Raabe. Evaluation of R-1234ze (Z) as drop-in replacement for R-245fa in Organic Rankine Cycles-From thermophysical properties to cycle performance. Energy, 93, (2015), pp. 266-274. https://doi.org/10.1016/j.energy.2015.09.035.

[6] J. S. Brown, C. Zilio, and A. Cavallini. The fluorinated olefin R-1234ze (Z) as a hightemperature heat pumping refrigerant. International Journal of Refrigeration, 32, (6), (2009), pp. 1412-1422. https://doi.org/10.1016/j.ijrefrig.2009.03.002.

[7] S. Zhang, H. Wang, and T. Guo. Evaluation of non-azeotropic mixtures containing HFOs as potential refrigerants in refrigeration and high-temperature heat pump systems. Science China Technological Sciences, 53, (7), (2010), pp. 1855-1861. https://doi.org/10.1007/s11431010-4008-2.

[8] Y. Higashi, S. Hayasaka, C. Shirai, and R. Akasaka. Measurements of P $\rho$ T properties, vapor pressures, saturated densities, and critical parameters for $R$ 1234ze (Z) and $\mathrm{R}$ 245fa. International Journal of Refrigeration, 52, (2015), pp. 100-108. https://doi.org/10.1016/j.ijrefrig.2014.12.007.

[9] L. Fedele, G. Di Nicola, J. S. Brown, S. Bobbo, and C. Zilio. Measurements and correlations of cis-1, 3, 3, 3-tetrafluoroprop-1-ene (R1234ze (Z)) saturation pressure. International Journal of Thermophysics, 35, (1), (2014), pp. 1-12. https://doi.org/10.1007/s10765-013-1553-5.

[10] J. S. Brown, G. Di Nicola, L. Fedele, S. Bobbo, and C. Zilio. Saturated pressure measurements of 3, 3, 3-trifluoroprop-1-ene (R1243zf) for reduced temperatures ranging from 0.62 to 0.98 . Fluid Phase Equilibria, 351, (2013), pp. 48-52. https://doi.org/10.1016/j.fluid.2012.09.036. 
[11] C. Kondou, R. Nagata, N. Nii, S. Koyama, and Y. Higashi. Surface tension of low GWP refrigerants R1243zf, R1234ze (Z), and R1233zd (E). International Journal of Refrigeration, 53, (2015), pp. 80-89. https://doi.org/10.1016/j.ijrefrig.2015.01.005.

[12] T. Katsuyuki. Measurements of vapor pressure and saturated liquid density for HFO1234ze(E) and HFO-1234ze(Z). Journal of Chemical \& Engineering Data, 61, (mar, 2016), pp. 1645-1648. https://doi.org/10.1021/acs.jced.5b01039.

[13] S. Lago, P. A. G. Albo, and J. S. Brown. Compressed liquid speed of sound measurements of cis-1, 3, 3, 3-tetrafluoroprop-1-ene (R1234ze (Z)). International Journal of Refrigeration, 65, (2016), pp. 55-59. https://doi.org/10.1016/j.ijrefrig.2016.02.003.

[14] R. Akasaka, Y. Higashi, A. Miyara, and S. Koyama. A fundamental equation of state for cis1, 3, 3, 3-tetrafluoropropene (R-1234ze (Z)). International Journal of Refrigeration, 44, (2014), pp. 168-176. https://doi.org/10.1016/j.ijrefrig.2013.12.018.

[15] J. S. Brown, C. Zilio, and A. Cavallini. Thermodynamic properties of eight fluorinated olefins. International Journal of Refrigeration, 33, (2), (2010), pp. 235-241. https://doi.org/10.1016/j.ijrefrig.2009.04.005.

[16] N. A. Lai. Equations of state for HFO-1234ze (E) and their application in the study on refrigeration cycle. International Journal of Refrigeration, 43, (2014), pp. 194-202. https://doi.org/10.1016/j.ijrefrig.2013.11.011.

[17] N. A. Lai and T. T. H. Phan. Review of the BACKONE equation of state and its applications. Molecular Physics, 115, (9-12), (2017), pp. 1041-1050. https://doi.org/10.1080/00268976.2016.1218562.

[18] L. Fedele, J. S. Brown, G. Di Nicola, S. Bobbo, and M. Scattolini. Measurements and correlations of cis-1333-Tetrafluoroprop-1-ene (R1234ze (Z)) subcooled liquid density and vapor-phase PvT. International Journal of Thermophysics, 35, (8), (2014), pp. 1415-1434. https://doi.org/10.1007/s10765-014-1730-1. 